\title{
Interaction of smoking and obesity susceptibility loci on adolescent BMI: The National Longitudinal Study of Adolescent to Adult Health
}

Kristin L. Young ${ }^{1,2,7^{*}}$, Misa Graff ${ }^{1,2}$, Kari E. North ${ }^{1,3}$, Andrea S. Richardson ${ }^{2,6}$, Karen L. Mohlke ${ }^{3,4}$, Leslie A. Lange ${ }^{3,4}$, Ethan M. Lange ${ }^{3,4}$, Kathleen M. Harris 2,5 and Penny Gordon-Larsen ${ }^{2,6}$

\begin{abstract}
Background: Adolescence is a sensitive period for weight gain and risky health behaviors, such as smoking. Genome-wide association studies (GWAS) have identified loci contributing to adult body mass index (BMI). Evidence suggests that many of these loci have a larger influence on adolescent BMI. However, few studies have examined interactions between smoking and obesity susceptibility loci on BMI. This study investigates the interaction of current smoking and established BMI SNPs on adolescent BMI. Using data from the National Longitudinal Study of Adolescent to Adult Health, a nationally-representative, prospective cohort of the US schoolbased population in grades 7 to 12 (12-20 years of age) in 1994-95 who have been followed into adulthood (Wave II 1996; ages 12-21, Wave III; ages 18-27), we assessed (in 2014) interactions of 40 BMI-related SNPs and smoking status with percent of the CDC/NCHS 2000 median BMI (\%MBMI) in European Americans $(n=5075)$, African Americans $(n=1744)$ and Hispanic Americans $(n=1294)$.
\end{abstract}

Results: Two SNPs showed nominal significance for interaction $(p<0.05)$ between smoking and genotype with \%MBMI in European Americans (EA) (rs2112347 (POC5): $\beta=1.98(0.06,3.90), p=0.04$ and near rs571312 (MC4R): $\beta 2.15(-0.03$, 4.33) $p=0.05)$; and one SNP showed a significant interaction effect after stringent correction for multiple testing in Hispanic Americans (HA) (rs1514175 (TNNI3K): $\beta 8.46$ (4.32, 12.60), $p=5.9 \mathrm{E}-05)$ ). Stratifying by sex, these interactions suggest a stronger effect in female smokers.

Conclusions: Our study highlights potentially important sex differences in obesity risk by smoking status in adolescents, with those who may be most likely to initiate smoking (i.e., adolescent females), being at greatest risk for exacerbating genetic obesity susceptibility.

Keywords: Adolescence, Obesity, Smoking, Gene-environment interaction

\section{Background}

Adolescence is a sensitive period for weight gain and health risk behaviors, such as smoking $[1,2]$. Obese smokers suffer 2.8-3.7 times greater mortality than those who are not obese and do not smoke [3]. In the US, nearly $90 \%$ of adult daily smokers begin smoking in

\footnotetext{
* Correspondence: kristin.young@unc.edu

'Department of Epidemiology, Gillings School of Global Public Health,

University of North Carolina, Chapel Hill, NC, USA

${ }^{2}$ Carolina Population Center, Gillings School of Global Public Health,

University of North Carolina, Chapel Hill, NC, USA

Full list of author information is available at the end of the article
}

their teens [4], and 400,000 adolescents become daily smokers every year [5]. Many adolescents, particularly females, use smoking as an appetite control strategy $[6,7]$. Females with greater body dissatisfaction are more likely to smoke [8], and obesity increases the likelihood of being highly addicted to nicotine during adolescence [9]. The effects of smoking differ by gender, in that smoking has a reported antiestrogenic effect in females, which may influence fat deposition [10, 11]. Adolescent smoking also varies by ethnicity, with Hispanic teens that have expressed concern about their weight being more likely to 
smoke than non-Hispanic teens [12]. While it has been demonstrated that weight is generally lower among adult smokers (ages 25-44 years), and higher among former adult smokers, this trend has not been observed in some younger smokers (ages 16-24 years) [13]. In addition, weight control effects of smoking may dissipate over time, as long-term smokers (20+ years) are heavier than never or former smokers, and heavy smokers are more likely to be obese than both other smokers and nonsmokers $[14,15]$.

Genome-wide association studies (GWAS) have identified single nucleotide polymorphisms (SNPs) contributing to variation in adult body mass index (BMI) [16-21], and evidence suggests these loci may have the greatest influence on adolescent BMI [22-28]. While many studies of obesity control for smoking status [29-32], few have examined the interaction between smoking and obesity susceptibility loci on BMI [33-36]. However, smoking has been implicated in appetite suppression through the $P O M C$ neural pathway [37], and loci in this pathway (POMC and MC4R) increase obesity risk [18, 38]. Our study examines the interaction between current smoking and 40 GWAS-identified and replicated SNPs associated with BMI in European descent adults [16, 18, 19, 21] on adolescent BMI in a multiethnic nationallyrepresentative cohort.

\section{Results}

Sample size, gender, mean age, percent median BMI (\%MBMI), smoking status and other descriptives are presented by ancestry in Table 1 . In the full sample, $11 \%$ of participants aged $12-21$ were obese (BMI $\geq 95$ th percentile), while a further $17 \%$ were overweight $\left(B M I \geq 85^{\text {th }}\right.$ percentile). African Americans (AA) had the highest percent obese (15.8\%), while Hispanic Americans (HA) had the highest percent overweight (21.9\%). Two-sample t-tests showed significantly higher BMI and \%MBMI in female, but not male, smokers than their non-smoking counterparts (Additional file 1: Table S1).

In main effects analyses of SNPs on \%MBMI among European Americans (EA), 33 of the established 39 BMI SNPs were directionally consistent with previous results [18], and 19 of those showed nominally significant association with \%MBMI (Additional file 2: Table S2). In AA, 12 out of 17 generalizable SNPs had effects on \%MBMI that were directionally consistent with the published literature, and 5 of these were nominally associated with \%MBMI (Additional file 3: Table S3). In our HA sample, 22 out of 31 established BMI loci in HA were directionally consistent with effects reported for BMI in EA adults, and 3 of these were nominally associated with \%MBMI (Additional file 4: Table S4). Interaction analyses were subsequently performed for these
33, 12 and 22 directionally consistent SNPs in EA, AA and $\mathrm{HA}$, respectively.

Two SNPs showed nominal $(p<0.05)$ evidence for interaction with smoking on \%MBMI in EA adolescents [rs2112347 (POC5): $\beta=1.98$ (0.06, 3.90), $p=0.04$ and near rs571312 (MC4R): $\beta 2.15(-0.03,4.33) p=0.05]$. One SNP had a significant interaction effect after the most stringent multiple test correction for 67 SNPs tested across three ancestries $(0.05 / 67=7.5 \mathrm{E}-04)$ in HA adolescents [rs1514175 (TNNI3K): $\beta=8.46$ (4.32, 12.60), $p=5.9 \mathrm{E}-05$ ] (Additional file 2: Tables S2, Additional file 3: Tables S3 and Additional file 4: Tables S4). Fig. 1 illustrates results from stratified analyses of these SNPs on \%MBMI by smoking status. In all cases, the estimated effect of the BMI-increasing allele was more pronounced in smokers (Fig. 1 and Table 2). None of these SNPs showed a main effect on smoking status (Additional file 2: Table S2, and Additional file 4: Table S4).

Examination of three-way interactions (SNP $\mathrm{x}$ smoking status $\times$ sex) for these three SNPs revealed only $M C 4 R$ had a nominally significant interaction effect $[\beta=5.44$ (1.11, 9.77), $p=0.014]$. Given the available sample sizes, it is not unexpected that statistical evidence supporting a three-way interaction would be difficult to detect. When we investigated SNP $\times$ smoking status interaction for MC4R in EA stratified by sex, we found a nominally significant interaction only in EA females $[\beta=4.75(1.73$, 7.77), $p=2.0 \mathrm{E}-03$; EA males $\beta=1.09$ (-4.23, 2.05), $p=$ 0.50]. In addition, when we stratified the effect of the obesity-risk genotype by sex and smoking status, we noted differential association with \%MBMI (Table 2). None of the three loci that showed nominal significance for interaction were associated $(p<0.05)$ with $\% \mathrm{MBMI}$ in female nonsmokers, while only $M C 4 R$ was nominally significant in male nonsmokers. Both TNNI3K $[\beta=6.41$ (0.92, 11.90), $p=0.02]$ and POC5 $[\beta=2.76(0.55,4.97)$, $p=0.01$ ] were nominally significant in $\mathrm{HA}$ and EA female smokers, respectively. $M C 4 R$ was significant after correction for multiple testing in EA female smokers $[\beta=5.48$ (3.06, 7.88), $p=8.4 \mathrm{E}-06]$ (Fig. 2).

\section{Discussion}

While previous research has shown that some smokingassociated loci influence BMI in smokers but not never smokers [39], and some established BMI loci are associated with smoking [40], few studies have examined the interaction between smoking and genetic risk for obesity on adolescent BMI. In this nationally representative study of adolescents, we identify two nominally significant obesity susceptibility variants in EA, rs2112347 (POC5) and rs571312 (MC4R), and one Bonferroni corrected significant variant in HA, rs1514175 (TNNI3K), which showed a comparatively stronger association in 
Table 1 Sex, age, BMI, \%MBMI and smoking status by ethnicity in the Add Health analytic sample

\begin{tabular}{|c|c|c|c|c|c|c|c|}
\hline \multirow[t]{2}{*}{ Characteristic } & \multirow{2}{*}{$\begin{array}{l}\text { All (N=8113) } \\
\text { Mean [95 \% Cl] /N (\%) }\end{array}$} & \multicolumn{2}{|c|}{ European Americans $(N=5075)$} & \multicolumn{2}{|c|}{ African Americans ( $N=1744)$} & \multicolumn{2}{|c|}{ Hispanic Americans $(N=1294)$} \\
\hline & & Smokers $(N=2065)$ & Nonsmokers $(N=3010)$ & Smokers $(N=324)$ & Nonsmokers $(N=1420)$ & Smokers $(N=367)$ & Nonsmokers $(N=927)$ \\
\hline Female & $4286(52.8)$ & $1102(53.4)$ & $1569(52.1)$ & $149(46.0)$ & $811(57.1)$ & $183(49.9)$ & $472(50.9)$ \\
\hline Age in years & $16.36[16.32,16.40]$ & $16.60[16.53,16.68]$ & $16.08[16.02,16.15]$ & $16.75[16.54,16.95]$ & $16.34[16.24,16.43]$ & $16.66[16.48,16.84]$ & $16.53[16.41,16.64]$ \\
\hline BMI & $23.45[23.34,23.57]$ & $23.18[22.96,23.40]$ & $22.94[22.78,23.12]$ & $24.97[24.31,25.63]$ & $24.13[23.83,24.43]$ & $23.65[24.12,25.27]$ & $24.70[23.32,23.99]$ \\
\hline$\%$ MBMI & $112.42[111.88,112.96]$ & $110.40[109.36,111.45]$ & $110.76[109.93,111.59]$ & $118.52[115.36,121.67]$ & $115.93[114.49,117.36]$ & $112.83[114.64,120.06]$ & $117.35[111.25,114.41]$ \\
\hline Self-reported BMI & $79(0.01)$ & $24(0.01)$ & $30(0.01)$ & $6(0.02)$ & $12(0.01)$ & $2(0.005)$ & $5(0.005)$ \\
\hline$\%$ Obese & $11 \%$ & $11 \%$ & $9 \%$ & $18 \%$ & $14 \%$ & $17 \%$ & $11 \%$ \\
\hline$\%$ Overweight & $17 \%$ & $17 \%$ & $16 \%$ & $19 \%$ & $20 \%$ & $22 \%$ & $19 \%$ \\
\hline \multicolumn{8}{|l|}{ Region of US } \\
\hline West & $1546(19.1)$ & $247(12.0)$ & $533(17.7)$ & $38(11.7)$ & $208(14.6)$ & $146(39.8)$ & $347(40.3)$ \\
\hline Midwest & $2286(28.2)$ & $824(39.9)$ & $1034(34.4)$ & $65(20.1)$ & $268(18.9)$ & 39 (10.6) & $56(6.0)$ \\
\hline South & 3234 (39.8) & $686(33.2)$ & $987(32.8)$ & $200(61.7)$ & $866(61.0)$ & $108(29.4)$ & $387(41.8)$ \\
\hline Northeast & $1047(12.9)$ & $308(14.9)$ & $456(15.1)$ & $21(6.5)$ & $78(5.50)$ & $74(20.2)$ & $110(11.9)$ \\
\hline \multicolumn{8}{|l|}{ African Americans } \\
\hline Highly Educated & & & & $49(15.1)$ & $291(20.5)$ & & \\
\hline \multicolumn{8}{|l|}{ Hispanic Americans } \\
\hline \multicolumn{8}{|l|}{ Ancestry } \\
\hline Puerto Rican & & & & & & 89 (24.3) & $134(14.5)$ \\
\hline Cuban & & & & & & $37(10.0)$ & $156(16.8)$ \\
\hline Mexican & & & & & & $181(49.3)$ & $475(51.3)$ \\
\hline Central/South American & & & & & & $27(7.4)$ & $92(9.9)$ \\
\hline Other Hispanic & & & & & & $33(9.0)$ & $70(7.5)$ \\
\hline \multicolumn{8}{|l|}{ Immigrant status } \\
\hline US Born & & & & & & $325(88.6)$ & $702(75.7)$ \\
\hline Non-US born & & & & & & $42(11.4)$ & $225(24.3)$ \\
\hline
\end{tabular}




\section{Effect of SNP on \%MBMI, stratified by ethnicity and smoking status}

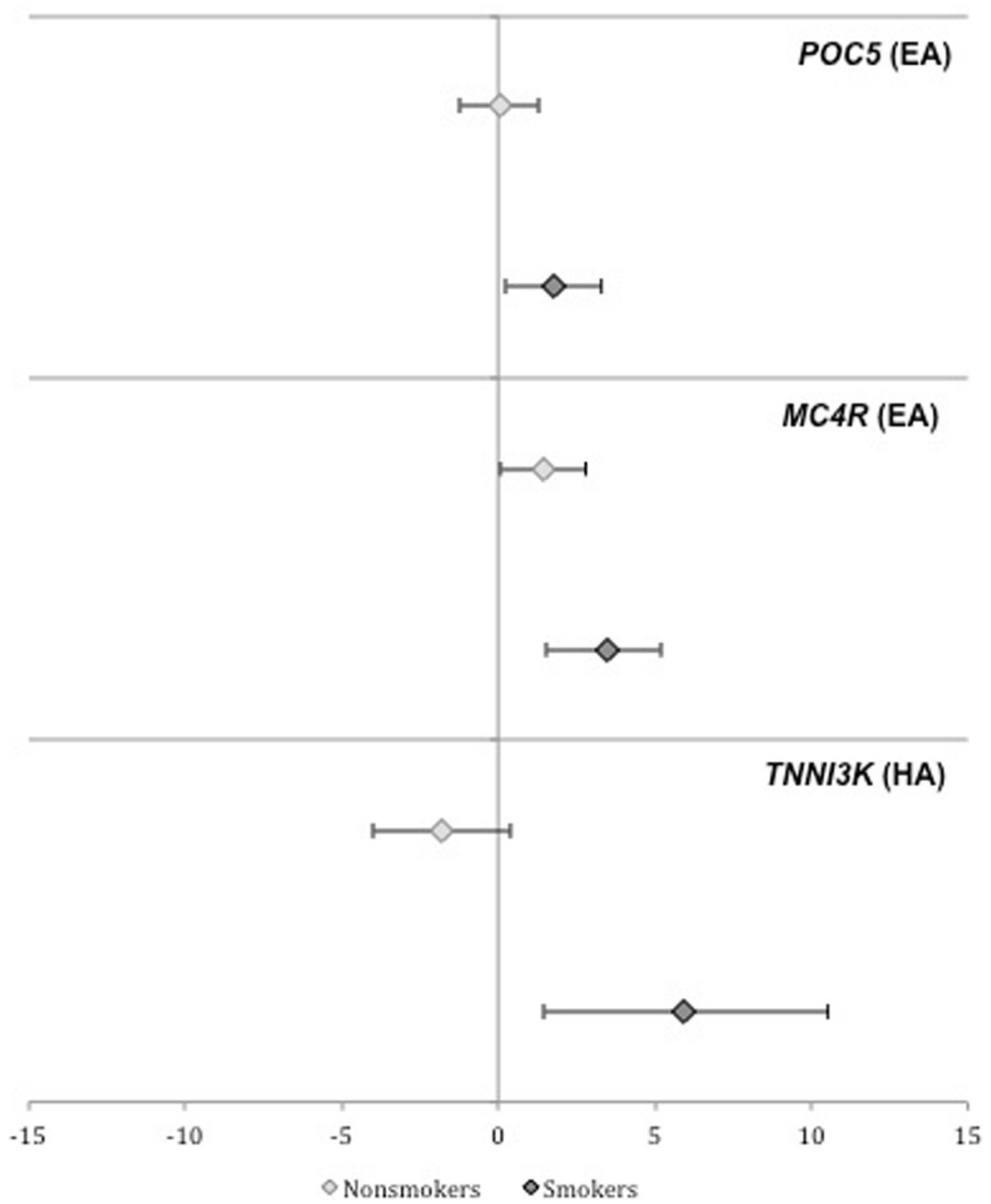

Fig. 1 Main effect of SNP on \%MBMl, stratified by ethnicity and smoking status, for those SNPs which showed a nominally significant ( $p<0.05$ ) interaction effect with smoking on \%MBMI

smokers vs. nonsmokers. Sex-stratified analyses revealed that, in general, smoking had a greater estimated effect on \%MBMI in adolescent females. In particular, EA female smokers who carry the $M C 4 R$ obesity susceptibility allele had a \%MBMI that was $5.48 \%$ higher than nonsmokers that carry the allele $(p=8.4 \mathrm{E}-06)$.

Our results are consistent with previous literature, in that not all obesity susceptibility loci showed a greater estimated positive effect in smokers (data not shown). Among EA, 20 of 33 BMI loci (61 \%) had a larger estimated effect in smokers versus nonsmokers, while 6 of 12 (50\%) and 12 of 22 BMI loci (55 \%) had a larger estimated effect in smokers versus nonsmokers among $\mathrm{AA}$ and $\mathrm{HA}$, respectively. In addition, the interaction effects we observed were generally more pronounced in women than in men. Previous analysis of 14 established BMI loci in EA and AA adults found no significant interaction $(p<0.05)$ between BMI
SNPs and smoking [33]. However, the authors noted a $3 \mathrm{x}$ increase in the estimated effect of the FTO (rs9939609) risk allele in EA female smokers, as well as a suggestive stronger estimated effect of the TMEM18 risk allele in AA female former/never smokers. No differential effects were reported for men. In our analysis, EA female smokers had a $1.22 \mathrm{x}$ increase in the estimated effect of the FTO risk allele, while EA male smokers had a 1.17 increased estimated effect of the FTO risk allele, compared to nonsmokers. We did not examine the effect of TMEM18 on BMI in AA, as that SNP did not generalize in the recent AA GWAS.

In our study, HA adolescent smokers carrying the obesity risk variant rs1514174 (near TNNI3K) were $8.46 \% \mathrm{MBMI}$ units larger than their non-smoking peers $(p=5.9 \mathrm{E}-05)$. The association of TNNI3K with obesity has been replicated in both in EA children 
Table 2 Stratified analysis of nominally significant $(p<0.05)$ SNP-by-smoking interactions on \%MBI in Add Health

\begin{tabular}{|c|c|c|c|c|}
\hline \multirow[b]{2}{*}{ POC5 (rs2112347) } & \multicolumn{2}{|c|}{ European American (EA) Nonsmokers } & \multicolumn{2}{|c|}{ European American (EA) Smokers } \\
\hline & Beta $[95 \% \mathrm{Cl}]$ & $p$ & Beta $[95 \% \mathrm{Cl}]$ & $p$ \\
\hline All & $0.04[-1.19,1.27]$ & 0.947 & $1.75[0.22,3.28]$ & 0.025 \\
\hline Females & $1.22[-0.49,2.93]$ & 0.16 & $2.76[0.55,4.97]$ & 0.014 \\
\hline Males & $-1.48[-3.26,0.30]$ & 0.102 & $1.03[-1.01,3.07]$ & 0.324 \\
\hline MC4R (rs571312) & Beta $[95 \% \mathrm{Cl}]$ & $p$ & Beta $[95 \% \mathrm{Cl}]$ & $p$ \\
\hline All & $1.46[0.09,2.83]$ & 0.036 & $3.50[1.78,5.22]$ & 7.54E-05 \\
\hline Females & $1.11[-0.79,3.01]$ & 0.253 & $5.48[3.07,7.89]$ & 8.37E-06 \\
\hline \multirow[t]{2}{*}{ Males } & $2.05[0.07,4.03]$ & 0.042 & $0.87[-1.58,3.32]$ & 0.489 \\
\hline & \multicolumn{2}{|c|}{ Hispanic American (HA) Nonsmokers } & \multicolumn{2}{|c|}{ Hispanic American (HA) Smokers } \\
\hline TNNI3K (rs1514175) & Beta $[95 \% \mathrm{Cl}]$ & $p$ & Beta $[95 \% \mathrm{Cl}]$ & $p$ \\
\hline All & $-1.80[-4.09,0.49]$ & 0.123 & $5.97[2.36,9.58]$ & 0.001 \\
\hline Females & $-2.00[-5.21,1.21]$ & 0.223 & $6.41[0.92,11.90]$ & 0.022 \\
\hline Males & $-1.78[-4.99,1.43]$ & 0.279 & $5.25[0.39,10.11]$ & 0.033 \\
\hline
\end{tabular}

Bold highlights nominally significant associations $(p \leq 0.05)$. Mixed effects model, BMI $=\beta+\beta S N P x S M K+\beta S N P+\beta S M K+\beta a g e+\beta s e x+f+s+\varepsilon$, Betas shown in table refer to $\beta$ SNPXSMK. \%MBMI = Percent of the CDC/NCHS 2000 median BMI

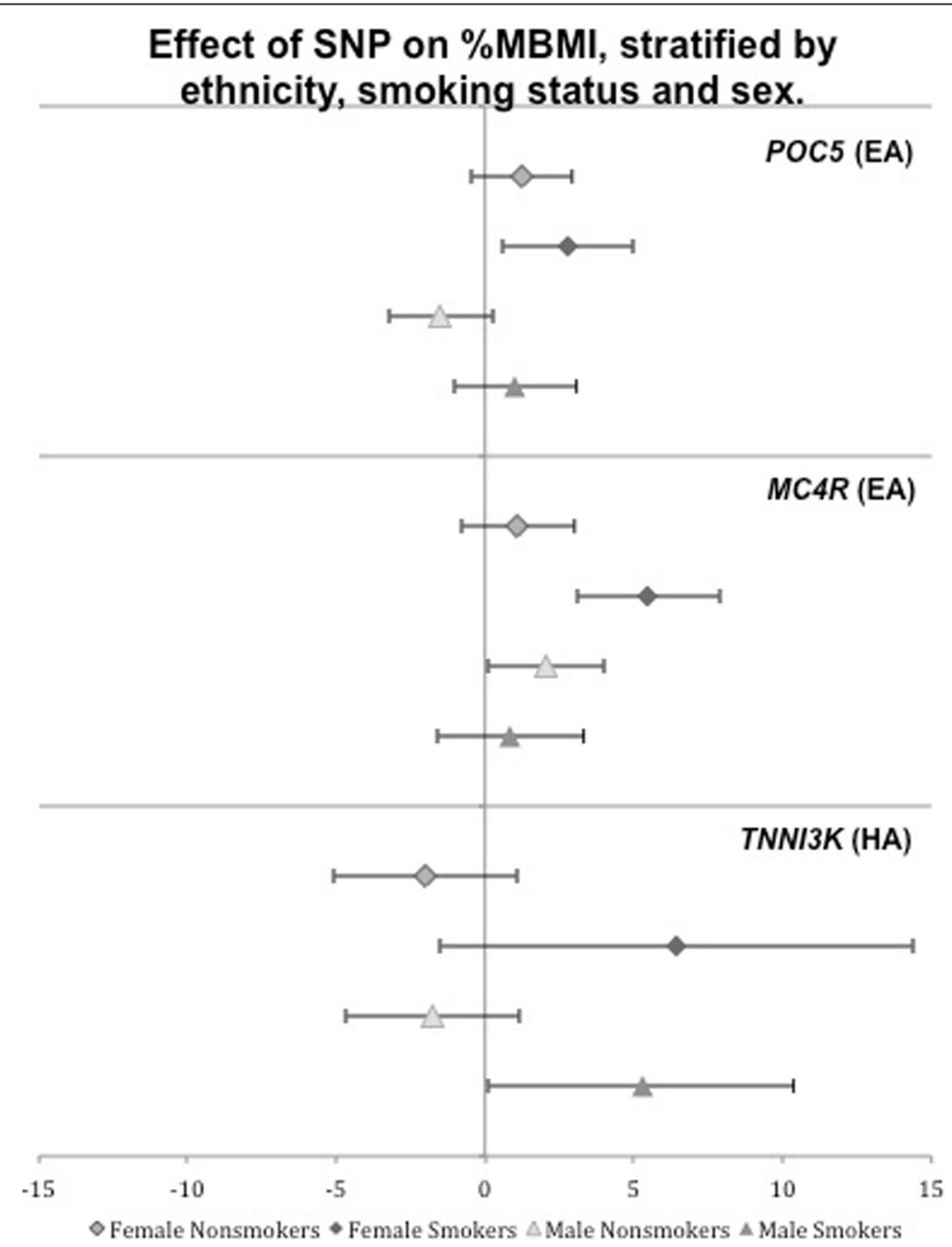

Fig. 2 Main effect of SNP on \%MBMl, stratified by ethnicity, smoking status, and sex, for those SNPs which showed a nominally significant $(p<0.05)$ interaction effect with smoking on \%MBMl 
[38, 41] and HA women [42]. TNNI3K has been associated with increased intake of fats and sugary foods in overweight or obese adults with Type 2 diabetes [43], and has been nominally associated $(p<0.05)$ with emotional and uncontrolled eating, suggesting a potential mechanism for influencing obesity [30]. In mouse models, TNNI3K expression has been linked to cardiac function and cardiac oxidative stress following myocardial infarction $[44,45]$. Both smoking and obesity increase systemic oxidative stress [46] and risk of cardiovascular disease (CVD), and the influence of TNNI3K on cardiac function suggests a possible biological pathway for this interaction.

Two loci showed nominally significant effects for interaction in EA adolescents, POC5 and MC4R. EA adolescents carrying the obesity risk variant rs2112347 (near POC5) were $1.98 \% \mathrm{MBMI}$ units larger than EA adolescent nonsmokers. Though the association between rs2112347 and BMI has been replicated [41, 47, 48], the biological mechanism through which rs2112347 influences obesity risk in not known [49]. This variant does lie, however, within $500 \mathrm{~kb}$ of $H M G C R$, a gene involved in lipid metabolism. Cigarette smoking increases dyslipidemia by inducing lipolysis in adipose tissue $[50,51]$, offering a promising avenue for future studies.

Finally, rs571312 near MC4R demonstrates the strongest influence on \%MBMI in EA female smokers $[\beta=5.48$ (3.06, 7.88), $p=8.4 \mathrm{E}-06]$, compared to EA female nonsmokers $[\beta 1.11(-0.79,3.01), p=0.253]$, EA male nonsmokers $[\beta 2.05(0.07,4.03), p=0.042]$, and EA male smokers $[\beta 0.87(-1.58,3.32), p=0.489]$ (Table 2, Fig. 2). Variants in MC4R are associated with monogenic obesity and show differential effects on BMI by sex and age, with a greater influence on adolescent females [22, 52]. MC4R is primarily expressed in the central nervous system [53], and plays a pivotal role in the leptin-melanocortin pathway regulating appetite, energy balance, and stress response [54]. Variants in and near $M C 4 R$ have been linked to metabolic syndrome $[55,56]$, percent body fat $[57,58]$, eating behavior [59], higher fat intake [60], and lower energy expenditure [61, 62]. In animal and some human models, variants near $M C 4 R$ have been shown to disproportionally affect adiposity in females [63-69]. While nicotine has been implicated in animal models as having a hypophagic effect on the leptin-melanocortin pathway influencing feeding behavior [37, 70], other research has shown a 2.9 fold increased risk of metabolic syndrome among smokers who carry a risk variant at a SNP (rs17782313) in high linkage disequilibrium (LD) with our MC4R SNP (rs571312, $R^{2}=0.955$ ) [69]. Rs17782313 has also been associated with a gender and temporal-specific effect on BMI, as well as smoking behavior [72]. Our results suggest $M C 4 R$ obesity risk variants might mitigate the appetite suppressant effect of nicotine in adolescent female smokers.
Add Health represents a unique sample during a sensitive developmental period, when risky health behaviors are being established. Add Health is a nationally representative sample of US adolescents who are being followed into adulthood. As such, our results can be considered generalizable to American adolescents entering adulthood in the late 1990s-early 2000s, but likely are not generalizable to adolescents at other time periods or in other countries. While we are fortunate to have measured heights and weights for the majority of our sample, current smoking was self-reported, though the questions used to assess smoking status in Add Health have been validated among adolescents. Our study was also limited by the lack of established BMI loci in all ancestries, particularly HA. We also recognize that we were possibly underpowered to detect effects due to small sample size [73], and that our approach cannot account for SNPs with an interaction effect but no measurable marginal effect on \%MBMI. Given our sample size $(N=5075)$ and other model parameters in EA, we have between 47 and $52 \%$ power to detect nominally significant interaction effects as large as those seen for the variants near POC5 ( $\beta 1.98)$ and MC4R ( $\beta 2.15)$. While our power is limited, pointing to the need to replicate our results in larger future studies, our results do suggest potential SNPs for further interrogation of the influence of smoking on BMI, particularly in adolescent females.

\section{Conclusions}

Our study highlights potentially important sex differences in obesity risk by smoking status in adolescents, with those who may be most likely to initiate smoking (i.e., adolescent females), being at greatest risk for poor health outcomes (exacerbating genetic obesity risk). Smoking influences central body fat distribution, and research suggests this effect could be particularly pronounced among women [74]. In addition, smokers have a greater risk of metabolic syndrome $[71,75]$ and dyslipidemia [76], as well as a much greater risk of mortality, particularly for CVD deaths among obese women under age 65 [3], highlighting the importance of targeting smoking early in adolescence to prevent poorer health in adulthood.

\section{Methods}

\section{Study sample}

The National Longitudinal Study of Adolescent to Adult Health (Add Health) is a nationally-representative, prospective cohort of adolescents from the US school-based population in grades 7 to 12 (12-20 years of age) in 1994-95 $(n=20,745)$ who have been followed into adulthood (Table 2). Add Health selected a systematic random sample of 80 high schools and 52 feeder middle 
schools, representative of US schools with respect to region, urbanicity, school type and size, and student demographics. Written informed consent was obtained from participants or a parent/guardian if the participant was a minor at the time of recruitment. Respondents were followed through Wave II (1996, $n=14,738$, age 13-21), Wave III (2001-2002, $n=15,197$, age 18-26) and most recently Wave IV (2007-2008, $n=15,701$, age 24-32), when respondents provided written informed consent for participation in genetic studies $(n=12,234)$. Add Health included a core sample plus subsamples of selected groups, including African American students with at least one parent with a college degree, collected under protocols approved by the Institutional Review Board at the University of North Carolina at Chapel Hill covering recruitment at all sites. The survey design and sampling frame have been described previously [77-79].

\section{Race/ethnicity}

Ancestry informative genetic markers were not available, so a self-reported race/ethnicity variable was constructed based on survey responses regarding ancestral background and family relationship status from both participants and their parents at Wave I. We used a three-category classification: non-Hispanic European American (EA), nonHispanic African American (AA), and Hispanic American (HA). Within HA, we generated additional variables to account for subpopulation (Cuban, Puerto Rican, Central/ South American, Mexican, or Other Hispanic), as well as foreign-born status (first generation immigrants versus those born in the US).

\section{Sibling relatedness}

Add Health oversampled related adolescents, resulting in 5524 related Wave I respondents living in 2639 households [80]. Familial relatedness was classified according to participant and parental self-report. Twin zygosity was confirmed by 11 molecular genetic markers [81].

\section{Genetic characterization}

The 40 SNPs genotyped in the current study were identified in published GWAS from the Genetic Investigation of Anthropometric Traits (GIANT) consortium for BMI in EA adults [16, 18, 19, 21]. Genotyping was performed using TaqMan assays and the ABI Prism 7900R Sequence Detection System (Applied Biosystems, Foster City, CA, USA). Primer sequences and TaqMan probes are available upon request. The genotype call rate ranged from 97.8 to $98.2 \%$ and the discordance rate between blind duplicates was $0.3 \%$. SNPs that failed tests for Hardy-Weinberg Equilibrium (HWE) $\quad(p<0.001)$ within race/ethnicity were excluded $(N=1, \mathrm{rs} 2922763)$ resulting in 39 SNPs for this analysis, as listed in Additional file 5: Table S5.

\section{Criteria for generalizability}

Across all groups, to the extent possible, generalizability was defined as similar direction of effect as reported in the literature and nominal statistical significance $(p<0.05)$ [24]. These criteria make generalization in the EA subpopulation straightforward, since these associations were defined in EA adults. A recent large AA GWAS [82], however, suggests that some SNPs fail to generalize, either due to limited power or because of linkage disequilibrium differences that fail to capture the signal of the functional variant. We thus excluded 15 SNPs in AA that have not shown evidence for generalization (i.e., SNP effect estimates were directionally inconsistent and evidence for association was $p>0.20$ in the recent AA GWAS) [82]. Similar results were reported in a recent HA GWAS of postmenopausal women, where only 9 of 32 established BMI loci showed evidence for association. As this analysis was conducted in a limited sample, however, we chose to retain all directionally consistent loci in our HA analysis [42]. In addition, SNPs with insufficient cell size for analysis $(n<10$ individuals per genotype) were excluded, leaving 33 SNPs in EA, 12 SNPs in AA, and 22 SNPs in HA for the interaction analyses (included SNPs highlighted in bold in Additional file 5: Table S5).

\section{Analytic sample}

At Wave IV, $59 \%(n=12,234)$ of Wave I $(n=20,745)$ respondents provided samples, with consent, from which DNA was extracted and genotyped $(n=12,066)$. To be eligible our study, individuals had to have at least $80 \%$ of their 39 SNPs genotyped $(n=11,448)$ and be between the ages of 12 and 21 years at either Wave II or III $(n=9129)$. Among the 9129 eligible adolescents, we excluded: the monozygotic twin with fewer genotyped loci $(n=139)$, individuals of Native American $(n=57)$, Asian $(n=436)$ or unclassified $(n$ $=112)$ race/ethnicity, pregnant $(n=110)$, disabled $(n=$ $47)$, and those missing data for geographic region ( $n$ $=67)$, BMI $(n=2)$, or current smoking $(n=46)$. The analytic sample was selected from waves II or III to capture the age range of 12-21 years, and all covariates match the wave at which BMI was measured. Our final analytic sample $(n=8113)$ included 5075 EA, $1744 \mathrm{AA}$, and $1294 \mathrm{HA}$.

\section{Body mass index (BMI)}

Weight and height were measured during in-home surveys using standardized procedures. BMI $\left(\mathrm{kg} / \mathrm{m}^{2}\right)$ was calculated using measured height and weight assessed at Waves II or III when participants were between the age of 12 and 21 years, with priority for younger age at measurement (Wave II: $n=7681$ ), unless the respondent was not seen at Wave II and was still between the ages of $12-21$ years at Wave III $(n=432)$. Selfreported heights and weights, which have been previously 
validated in Add Health, were substituted for those who refused measurement and/or weighed more than the scale capacity (Wave II $n=55$; Wave III $n=24$ ) [83]. Due to changes in weight and height with growth and development, BMI varies by age and sex, which necessitates using age- and sex-specific BMI Z-scores relative to a reference such as the US the CDC/NCHS 2000 growth curves [84]. However, these growth curves do not represent the tails of the distribution well, which is a particular issue in a cohort with considerable upward skew in distribution relative to the $\mathrm{CDC} / \mathrm{NCHS} 2000$ healthy reference. A strategy to deal with this is to use percent of the CDC/NCHS 2000 median [85], which also has the benefit of ease in interpretation relative to the Z-score. Accordingly, our outcome for all analyses was the percent of the $\mathrm{CDC} /$ NCHS 2000 median BMI (\%MBMI).

\section{Current smoking}

Current smoking was based on self-report, which has been previously validated among adolescents [86], and was defined as smoking at least 1 day in the last 30 days. $[2,87,88]$ Current smoking status was queried at Waves II $\left(\mathrm{N}_{\text {current_smokers }}=2589\right)$ and III $\left(\mathrm{N}_{\text {current_smokers }}=2377\right)$, to match the wave at which BMI was measured. To measure the effect of BMI-related SNPs on current smoking, we performed main effects logistic regression using smoking status as the outcome and SNP as predictor, stratified by ancestry (Additional file 2: Tables S2, Additional file 3: Tables S3 and Additional file 4: Tables S4).

\section{Statistical analysis}

In ancestry-stratified, multivariable interaction (SNPxsmoking) models with \%MBMI as the outcome, we controlled for age, sex, geographic region, and self-reported heights and weights using Stata (v13.1, Stata Corp, College Station, Texas). In non-EA populations, we also controlled for oversampling of adolescents from highly-educated African American families $(n=355)$, and Hispanic subpopulation: Cuban $(n=193)$, Puerto Rican $(n=223)$, Central/South American $(n=119)$, Mexican $(n=656)$, and other Hispanic $(n=102)$, as well as an indicator for foreign-born status $(n=267)$. Sample design effects and familial relatedness were accounted for by including separate random effects for school and family. When a nominally significant interaction $(p<0.05)$ was detected, we ran additional interaction models (SNP $\mathrm{x}$ smoking status, stratified by sex; and SNP $x$ smoking status $x$ sex), and examined SNP effects in models stratified by smoking status and sex, to facilitate interpretation. To correct for multiple testing, we applied a Bonferroni correction equal to 0.05 /number of SNPs tested in each group $(0.05 / 33=0.0015$ in EA, 0.05/ $22=0.0023$ in $\mathrm{HA}, 0.05 / 12=0.0042$ in AA).

\section{Availability of data and materials}

Add Health adheres to the NIH policy on data sharing, but due to the sensitive nature of Add Health data, access is limited and governed by the Add Health data management security plan to ensure respondent confidentiality. For this reason, the distribution of data is limited to a public-use dataset for a subset of respondents, and a restricted-use dataset distributed only to certified researchers committed to maintaining limited access. Add Health is currently in the process of submitting genetic data to $\mathrm{dbGaP}$, which will be made available to researchers meeting both dbGaP and Add Health data use requirements. More information can be found here: http://www.cpc.unc.edu/projects/addhealth.

\section{Additional files}

Additional file 1: Table S1. Two-sample t-test of differences in BMI and \%MBMI by smoking status, stratified by ancestry and sex. (DOCX $72 \mathrm{~kb}$ )

Additional file 2: Table S2. Results of SNPxSmoking on \%MBMI (Interaction), SNP on \%MBMI (Main effects), and SNP on smoking in European American adolescents in Add Health. (DOCX $41 \mathrm{~kb}$ )

Additional file 3: Table S3. Results of SNPXSmoking on \%MBMI (Interaction), SNP on \%MBMI (Main effects), and SNP on smoking in African American adolescents in Add Health. (DOCX 35 kb)

Additional file 4: Table S4. Results of SNPxSmoking on \%MBMI (Interaction), SNP on \%MBMI (Main effects), and SNP on smoking in Hispanic American adolescents in Add Health. (DOCX 40 kb)

Additional file 5: Table S5. Established BMl loci used in present analysis. (DOCX $31 \mathrm{~kb}$ )

\section{Abbreviations}

BMI: Body mass index; \%MBMI: Percent median BMI; SNP: Single nucleotide polymorphism; EA: European American; AA: African American; HA: Hispanic American; CVD: Cardiovascular disease; GWAS: Genome Wide Assocation Study; HWE: Hardy Weinberg Equilibrium.

\section{Competing interests}

This work was funded by National Institutes of Health grant R01HD057194. There were no potential or real conflicts of financial or personal interest with the financial sponsors of the research project. Research sponsors had no role in study design; collection, analysis, or interpretation of data; writing the manuscript; or the decision to submit the manuscript for publication.

\section{Authors' contributions}

$P G L, K M H, K E N, E M L$, and KLY contributed to study design; KLY, MG and ASR to data analysis, KLY, KEN, EML, LAL, KLM, and PGL contributed to data interpretation; and $K L Y, K E N$, and PGL contributed to writing the manuscript. All authors provided critical evaluation of the manuscript, had full access to all data in the study, and take responsibility for data integrity and analysis accuracy. All authors read and approved the final manuscript.

\section{Acknowledgement}

We thank Amy Perou of the BioSpecimen Processing facility and Jason Luo of the Mammalian Genotyping Core at the University of North Carolina at Chapel Hill. This work was funded by National Institutes of Health grant R01HD057194. This research uses data from Add Health, a program project directed by Kathleen Mullan Harris and designed by J. Richard Udry, Peter S Bearman, and Kathleen Mullan Harris at the University of North Carolina at Chapel Hill, and funded by grant P01-HD31921 from the Eunice Kennedy Shriver National Institute of Child Health and Human Development, with cooperative funding from 23 other federal agencies and foundations. Special acknowledgement is due to Ronald R. Rindfuss and Barbara Entwistle for assistance in the original design. Information on how to obtain Add Health 
data files is available on the Add Health website (http://www.cpc.unc.edu/ addhealth). No direct support was received from grant P01-HD31921 for this analysis. We are grateful to the Carolina Population Center for general support. Preliminary analysis of this work has been presented at The Obesity Society Annual Meeting (2012)

\section{Author details}

${ }^{1}$ Department of Epidemiology, Gillings School of Global Public Health, University of North Carolina, Chapel Hill, NC, USA. ${ }^{2}$ Carolina Population Center, Gillings School of Global Public Health, University of North Carolina, Chapel Hill, NC, USA. ${ }^{3}$ Carolina Center for Genome Sciences, Gillings School of Global Public Health, University of North Carolina, Chapel Hill, NC, USA. ${ }^{4}$ Department of Genetics, Gillings School of Global Public Health, University of North Carolina, Chapel Hill, NC, USA. ${ }^{5}$ Department of Sociology, Gillings School of Global Public Health, University of North Carolina, Chapel Hill, NC, USA. ${ }^{6}$ Department of Nutrition, Gillings School of Global Public Health, University of North Carolina, Chapel Hill, NC, USA. ${ }^{7} 137$ East Franklin Street, Suite 306, Chapel Hill, NC 27514, USA.

\section{Received: 5 May 2015 Accepted: 29 October 2015}

Published online: 04 November 2015

\section{References}

1. Harris KM, Gordon-Larsen P, Chantala K, Udry JR. Longitudinal trends in race/ethnic disparities in leading health indicators from adolescence to young adulthood. Arch Pediatr Adolesc Med. 2006;160(1):74-81. doi:10.1001/archpedi.160.1.74.

2. Dierker L, Mermelstein R. Early emerging nicotine-dependence symptoms: A signal of propensity for chronic smoking behavior in adolescents. J Pediatr. 2010;156(5):818-22. doi:10.1016/j.jpeds.2009.11.044.

3. Freedman DM, Sigurdson AJ, Rajaraman P, Doody MM, Linet MS, Ron E. The mortality risk of smoking and obesity combined. Amer J Prev Med. 2006;31(5):355-62. doi:10.1016/j.amepre.2006.07.022.

4. U.S. Department of Health and Human Services. Preventing tobacco use among youth and young adults: A report from the Surgeon General. http://www.cdc.gov. 2012. Accessed August 12, 2013.

5. Administration Substance Abuse and Mental Health Services. Results from the 2011 National Survey on Drug Use and Health: Summary of National Findings. http://www.samhsa.gov/data/nsduh/2k11 results/nsduhresults2011.htm. 2012. Accessed August 12, 2013.

6. Cawley J, Markowitz S, Tauras J. Lighting up and slimming down: The effects of body weight and cigarette prices on adolescent smoking initiation. J Health Econ. 2004;23(2):293-311.

7. Harakeh Z, Engels RCME, Monshouwer K, Hanssen PF. Adolescent's weight concerns and the onset of smoking. Subst Use Misuse. 2010;45(12):1847-60. doi:10.3109/10826081003682149.

8. Kaufman AR, Augustson EM. Predictors of regular cigarette smoking among adolescent females: Does body image matter? Nicotine Tob Res. 2008;10(8):1301-9. doi:10.1080/14622200802238985.

9. Hussaini AE, Nicholson LM, Shera D, Stettler N, Kinsman S. Adolescent obesity as a risk factor for high-level nicotine addiction in young women. J Adolesc Health. 2011:49(5):511-7. doi:10.1016/j.jadohealth.2011.04.001.

10. Pauly JR. Gender differences in tobacco smoking dynamics and the neuropharmacological actions of nicotine. Front Biosci. 2007;13:505-16.

11. Windham GC, Mitchell P, Anderson M, Lasley BL. Cigarette smoking and effects on hormone function in premenopausal women. Environ Health Perspect. 2005;113(10):1285-90.

12. Weiss JW, Merrill V, Gritz ER. Ethnic variation in the association between weight concern and adolescent smoking. Addict Behav. 2007;32(10):2311-6. doi:10.1016/j.addbeh.2007.01.020

13. Mackay DF, Gray L, Pell JP. Impact of smoking and smoking cessation on overweight and obesity: Scotland-wide, cross-sectional study on 40,036 participants. BMC Public Health. 2013;13:348. doi:10.1186/1471-2458-13-348.

14. Chiolero A, Jacot-Sadowski I, Faeh D, Paccaud F, Cornuz J. Association of cigarettes smoked daily with obesity in a general adult population. Obesity. 2007;15(5):1311-8. doi:10.1038/oby.2007.153.

15. Clair C, Chiolero A, Faeh D, Cornuz J. Dose-dependent positive association between cigarette smoking, abdominal obesity and body fat: cross-sectional data from a population-based survey. BMC Public Health. 2011;11:23. doi:10.1186/1471-2458-11-23.
16. Willer CJ, Speliotes EK, Loos RJF, Li S, Lindgren CM, Heid IM, et al. Six new loci associated with body mass index highlight a neuronal influence on body weight regulation.

Nat Genet. 2008;41(1):25-34. doi:10.1038/ng.287.

17. Heid IM, Jackson AU, Randall JC, Winkler TW, Qi L, Steinthorsdottir V, et al. Meta-analysis identifies 13 new loci associated with waist-hip ratio and reveals sexual dimorphism in the genetic basis of fat distribution. Nat Genet. 2010;42(11):949-60.

doi:10.1038/ng.685.

18. Speliotes EK, Willer CJ, Berndt SI, Thorleifsson G, Jackson AU, Lango Allen H, et al. Association analyses of 249,796 individuals reveal 18 new loci associated with body mass index. Nat Genet. 2010;42(11):937-48. doi:10.1038/ng.686.

19. Heard-Costa NL, Zillikens MC, Monda KL, Johansson A, Harris TB, Fu M, et al. NRXN3 Is a novel locus for waist circumference: A genome-wide association study from the CHARGE Consortium. PLoS Genet. 2009;5(6):e1000539.

20. Lindgren CM, Heid IM, Randall JC, Lamina C, Steinthorsdottir V, Qi L, et al. Genome-wide association scan meta-analysis identifies three loci influencing adiposity and fat distribution. PLoS Genet. 2009;5(6):e1000508. doi:10.1371/journal.pgen.1000508.

21. Thorleifsson G, Walters GB, Gudbjartsson DF, Steinthorsdottir $V$, Sulem $P$, Helgadottir A, et al. Genome-wide association yields new sequence variants at seven loci that associate with measures of obesity. Nat Genet. 2008;41(1):18-24.

22. Kvaløy K, Kulle B, Romundstad P, Holmen TL. Sex-specific effects of weightaffecting gene variants in a life course perspective-The HUNT Study, Norway. Int J Obes Relat Metab Disord. 2013;37(9):1221-9. doi:10.1038/ijo.2012.220.

23. Elks CE, Loos RJF, Hardy R, Wills AK, Wong A, Wareham NJ, et al. Adult obesity susceptibility variants are associated with greater childhood weight gain and a faster tempo of growth: the 1946 British Birth Cohort Study. Amer J Clin Nutr. 2012;95(5):1150-6. doi:10.3945/ajcn.111.027870.

24. Graff M, North KE, Mohlke KL, Lange LA, Luo J, Harris KM, et al. Estimation of genetic effects on BMI during adolescence in an ethnically diverse cohort: The National Longitudinal Study of Adolescent Health. Nutr Diab. 2012;2(9):e47-8. doi:10.1038/nutd.2012.20.

25. Graff M, Ngwa JS, Workalemahu T, Homuth G, Schipf S, Teumer A, et al. Genome-wide analysis of BMI in adolescents and young adults reveals additional insight into the effects of genetic loci over the life course. Hum Mol Genet. 2013;22(17):3597-607. doi:10.1093/hmg/ddt205.

26. Llewellyn $\mathrm{CH}$, Trzaskowski M, Plomin R, Wardle J. Finding the missing heritability in pediatric obesity: the contribution of genome-wide complex trait analysis. Int J Obes Relat Metab Disord. 2013;37(11):1506-9. doi:10.1038/ijo.2013.30.

27. Zhao JH, Bradfield JP, Li MD, Wang K, Zhang HW, Kim CE, et al. The role of obesity-associated loci identified in genome-wide association studies in the determination of pediatric BMI. Obesity. 2009;17(12):2254-7. doi:10.1038/oby.2009.159.

28. Loos RJF, Lindgren CM, Li S, Wheeler E, Zhao JH, Prokopenko I, et al. Common variants near MC4R are associated with fat mass, weight and risk of obesity. Nat Genet. 2008;40(6):768-75. doi:10.1038/ng.140.

29. Bradshaw PT, Monda KL, Stevens J. Metabolic syndrome in healthy obese, overweight, and normal weight individuals: the Atherosclerosis Risk in Communities Study. Obesity. 2013;21(1):203-9. doi:10.1002/oby.20248.

30. Cornelis MC, Rimm EB, Curhan GC, Kraft P, Hunter DJ, Hu FB, et al. Obesity susceptibility loci and uncontrolled eating, emotional eating and cognitive restraint behaviors in men and women. Obesity. 2013:n/a-n/a. doi:10.1002/ oby.20592.

31. Demerath EW, Lutsey PL, Monda KL, Linda Kao WH, Bressler J, Pankow JS, et al. Interaction of FTO and physical activity level on adiposity in African-American and European-American adults: the ARIC Study. Obesity. 2011;19(9):1866-72. doi:10.1038/oby.2011.131.

32. Dong C, Beecham A, Slifer S, Wang L, McClendon MS, Blanton SH, et al. Genome-wide linkage and peak-wide association study of obesityrelated quantitative traits in Caribbean Hispanics. Hum Genet. 2011;129(2):209-19. doi:10.1007/s00439-010-0916-2.

33. Fesinmeyer MD, North KE, Lim U, Bůžková $P$, Crawford DC, Haessler J, et al. Effects of smoking on the genetic risk of obesity: The population architecture using genomics and epidemiology study. BMC Med Genet. 2013;14:6. doi:10.1186/1471-2350-14-6. 
34. Velez Edwards DR, Naj AC, Monda K, North KE, Neuhouser M, Magvanjav O, et al. Gene-environment interactions and obesity traits among postmenopausal African-American and Hispanic women in the Women's Health Initiative SHARe Study. Hum Genet. 2012;132(3):323-36. doi:10.1007/s00439-012-1246-3.

35. Edwards TL, Velez Edwards DR, Villegas R, Cohen SS, Buchowski MS, Fowke JH, et al. HTR1B, ADIPOR1, PPARGC1A, and CYP19A1 and obesity in a cohort of Caucasians and African Americans: an evaluation of gene-environment interactions and candidate genes. Am J Epidemiol. 2011;175(1):11-21. doi:10.1093/aje/kwr272.

36. Lee S, Kim CM, Kim HJ, Park HS. Interactive effects of main genotype, caloric intakes, and smoking status on risk of obesity. Asia Pac J Clin Nutr. 2011:20(4):563-71.

37. Mineur YS, Abizaid A, Rao Y, Salas R, DiLeone RJ, Gündisch D, et al. Nicotine decreases food intake through activation of POMC neurons. Science. 2011;332(6035):1330-2. doi:10.1126/science.1201889.

38. Bradfield JP, Taal HR, Timpson NJ, Scherag A, Lecoeur C, Warrington NM, et al. A genome-wide association meta-analysis identifies new childhood obesity loci. Nat Genet. 2012;44(5):526-31. doi:10.1038/ng.2247.

39. Freathy RM, Kazeem GR, Morris RW, Johnson PC, Paternoster L, Ebrahim S, et al. Genetic variation at CHRNA5-CHRNA3-CHRNB4 interacts with smoking status to influence body mass index. Int J Epidemiol. 2011:40(6):1617-28. doi:10.1093/ije/dyr077.

40. Thorgeirsson TE, Stefansson K. Genetics of smoking behavior and its consequences: The role of nicotinic acetylcholine receptors. Biol Psychiatry 2008;64(11):919-21. doi:10.1016/j.biopsych.2008.09.010.

41. Zhao J, Bradfield JP, Zhang H, Sleiman PM, Kim CE, Glessner JT, et al. Role of BMl-associated loci identified in GWAS meta-analyses in the context of common childhood obesity in European Americans. Obesity. 2011;19(12):2436-9. doi:10.1038/oby.2011.237.

42. Graff M, Fernández-Rhodes L, Liu S, Carlson C, Wassertheil-Smoller S, Neuhouser M, et al. Generalization of adiposity genetic loci to US Hispanic women. Nutr Diab. 2013;3:e85. doi:10.1038/nutd.2013.26.

43. McCaffery JM, Papandonatos GD, Peter I, Huggins GS, Raynor HA, Delahanty LM, et al. Obesity susceptibility loci and dietary intake in the Look AHEAD Trial. Amer J Clin Nutr. 2012;95(6):1477-86. doi:10.3945/ajcn.111.026955.

44. Lodder EM, Scicluna BP, Milano A, Sun AY, Tang H, Remme CA, et al. Dissection of a quantitative trait locus for PR interval duration identifies TNNI3K as a novel modulator of cardiac conduction. PLoS Genet. 2012;8:e1003113. doi:10.1371/journal.pgen. 1003113.

45. Vagnozzi RJ, Gatto GJ, Kallander LS, Hoffman NE, Mallilankaraman K, Ballard $V L$, et al. Inhibition of the cardiomyocyte-specific kinase TNNI3K limits oxidative stress, injury, and adverse remodeling in the ischemic heart. Sci Transl Med. 2013;5(207):207ra141. doi:10.1126/scitranslmed.3006479.

46. Keaney JF, Larson MG, Vasan RS, Wilson PW, Lipinska I, Corey D, et al. Obesity and systemic oxidative stress clinical correlates of oxidative stress in the Framingham Study. Arterioscler Thromb Vasc Biol. 2003;23(3):434-9. doi:10.1161/01.ATV.0000058402.34138.11

47. Juonala M, Juhola J, Magnussen CG, Würtz P, Viikari JS, Thomson R, et al. Childhood environmental and genetic predictors of adulthood obesity: The cardiovascular risk in young Finns study. J Clin Endocrinol Metab. 2011:96(9):E1542-9. doi:10.1210/jc.2011-1243.

48. Okada Y, Kubo M, Ohmiya H, Takahashi A, Kumasaka N, Hosono N, et al. Common variants at CDKAL1 and KLF9 are associated with body mass index in East Asian populations. Nat Genet. 2012;44(3):302-6. doi:10.1038/ng.1086

49. Speakman JR. Functional analysis of seven genes linked to body mass index and adiposity by genome-wide association studies: A Review. Hum Hered. 2013;75(2-4):57-79. doi:10.1159/000353585.

50. Hellerstein MK, Benowitz NL, Neese RA. Effects of cigarette smoking and its cessation on lipid metabolism and energy expenditure in heavy smokers. J Clin Invest. 1994;93(1):265-72. doi:10.1172/JCl116955.

51. Audrain-McGovern J, Benowitz NL. Cigarette smoking, nicotine, and body weight. Clin Pharmacol Ther. 2011;90(1):164-8. doi:10.1038/ clpt.2011.10562.

52. Grant SFA, Bradfield JP, Zhang H, Wang K, Kim CE, Annaiah K, et al. Investigation of the locus near MC4R with childhood obesity in Americans of European and African ancestry. Obesity. 2009;17(7):1461-5. doi:10.1038/oby.2009.53.

53. Garver WS, Newman SB, Gonzales-Pacheco DM, Castillo JJ, Jelinek D, Heidenreich RA, et al. The genetics of childhood obesity and interaction with dietary macronutrients. Genes Nutr. 2013;8(3):271-87. doi:10.1007/ s12263-013-0339-5.
54. Horstmann A, Kovacs P, Kabisch S, Boettcher $Y$, Schloegl H, Tönjes A, et al. Common genetic variation near MC4R has a sex-specific impact on human brain structure and eating behavior. PLoS One. 2013;8(9):e74362. doi:10.1371/journal.pone.0074362.

55. Lubrano-Berthelier C, Cavazos M, Dubern B, Shapiro A, Stunff CL, Zhang S, et al. Molecular genetics of human obesity-associated MC4R mutations. Ann N Y Acad Sci. 2003;994:49-57. doi:10.1111/j.1749-6632.2003.tb03161.x.

56. Dušátková L, Zamrazilová H, Sedláčková B, Včelák J, Hlavatý P, Aldhoon Hainerová I, et al. Association of obesity susceptibility gene variants with metabolic syndrome and related traits in 1,443 Czech adolescents. Folia Biol (Praha). 2013;59(3):123-33.

57. den Hoed M, Luan J, Langenberg C, Cooper C, Sayer AA, Jameson K, et al. Evaluation of common genetic variants identified by GWAS for early onset and morbid obesity in population-based samples. Int J Obes Relat Metab Disord. 2013;37(2):191-6. doi:10.1038/ijo.2012.34.

58. Kilpeläinen TO, Zillikens MC, Stančáková A, Finucane FM, Ried JS, Langenberg C, et al. Genetic variation near IRSI associates with reduced adiposity and an impaired metabolic profile. Nat Genet. 2011;43(8):753-60. doi:10.1038/ng.866

59. Branson R, Potoczna N, Kral JG, Lentes KU, Hoehe MR, Horber FF. Binge eating as a major phenotype of melanocortin 4 receptor gene mutations. N Engl J Med. 2003;348(12):1096-103. doi:10.1056/NEJMoa021971.

60. Qi L, Kraft P, Hunter D, Hu FB. The common obesity variant near MC4R gene is associated with higher intakes of total energy and dietary fat, weight change and diabetes risk in women. Hum Mol Genet. 2008;17(22):3502-8. doi:10.1093/hmg/ddn242.

61. Cole SA, Butte NF, Voruganti VS, Cai G, Haack K, Kent JW, et al. Evidence that multiple genetic variants of MC4R play a functional role in the regulation of energy expenditure and appetite in Hispanic children. Am J Clin Nutr. 2010;91(1):191-9. doi:10.3945/ajen.2009.28514.

62. Cai G, Cole SA, Butte N, Bacino C, Diego V, Tan K, et al. A quantitative trait locus on chromosome 18q for physical activity and dietary intake in Hispanic children. Obesity. 2006;14(9):1596-604. doi:10.1038/oby.2006.184.

63. Hardy R, Wills AK, Wong A, Elks CE, Wareham NJ, Loos RJ, et al. Life course variations in the associations between FTO and MC4R gene variants and body size. Hum Mol Genet. 2010;19(3):545-52. doi:10.1093/hmg/ddp504.

64. Orkunoglu-Suer FE, Harmon BT, Gordish-Dressman H, Clarkson PM, Thompson PD, Angelopoulos TJ, et al. MC4R variant is associated with $\mathrm{BMI}$ but not response to resistance training in young females. Obesity. 2010;19(3):662-6. doi:10.1038/oby.2010.180.

65. Hinney A, Volckmar A-L, Knoll N. Melanocortin-4 receptor in energy homeostasis and obesity pathogenesis. Prog Mol Biol Transl Sci. 2013:114:147-91. doi:10.1016/B978-0-12-386933-3.00005-4.

66. Sina M, Hinney A, Ziegler A, Neupert T, Mayer $H$, Siegfried $W$, et al. Phenotypes in three pedigrees with autosomal dominant obesity caused by haploinsufficiency mutations in the melanocortin-4 receptor gene. Am J Hum Genet. 1999;65(6):1501-7. doi:10.1086/302660.

67. Dempfle A, Hinney A, Heinzel-Gutenbrunner M, Raab M, Geller $F$, Gudermann T, et al. Large quantitative effect of melanocortin-4 receptor gene mutations on body mass index. J Med Genet. 2004:41(10):795-800. doi:10.1136/jmg.2004.018614.

68. Dougkas A, Yaqoob P, Givens DI, Reynolds CK, Minihane AM. The impact of obesity-related SNP on appetite and energy intake. Br J Nutr. 2013;110(6):1151-6. doi:10.1017/S0007114513000147.

69. Vogel CIG, Boes T, Reinehr T, Roth CL, Scherag S, Scherag A, et al. Common variants near MC4R: exploring gender effects in overweight and obese children and adolescents participating in a lifestyle intervention. Obes Facts. 2011;4(1):67-75. doi:10.1159/000324557.

70. Martinez de Morentin PB, Whittle AJ, Fernø J, Nogueiras R, Diéguez C, Vidal-Puig $A$, et al. Nicotine induces negative energy balance through hypothalamic AMPactivated protein kinase. Diabetes. 2012;61(4):807-17. doi:10.2337/db11-1079.

71. Yang C-W, Li C-I, Liu C-S, Bau DT, Lin CH, Lin WY, et al. The joint effect of cigarette smoking and polymorphisms on LRP5, LEPR, near MC4R and SH2B1 genes on metabolic syndrome susceptibility in Taiwan. Mol Biol Rep. 2012;40(1):525-33. doi:10.1007/s11033-012-2089-7.

72. Thorgeirsson TE, Gudbjartsson DF, Sulem P, Besenbacher S, Styrkarsdottir U, Thorleifsson G, et al. A common biological basis of obesity and nicotine addiction. Translational Psychiatry. 2013;3(10):e308-7. doi:10.1038/tp.2013.81.

73. Hunter D. Gene-environment interactions in human diseases. Nat Rev Genet. 2005;6(4):287-98. doi:10.1038/nrg1578. 
74. Kwok S, Canoy D, Soran H, Ashton DW, Lowe GD, Wood D, et al. Body fat distribution in relation to smoking and exogenous hormones in British women. Clin Endocrinol (Oxf). 2012;77(6):828-33. doi:10.1111/j.13652265.2012.04331.x

75. Sun K, Liu J, Ning G. Active smoking and risk of metabolic syndrome: A meta-analysis of prospective studies. PLoS One. 2012;7(10):e47791. doi:10.1371/journal.pone.0047791.

76. Ordovas JM, Robertson R, Cléirigh EN. Gene-gene and gene-environment interactions defining lipid-related traits. Curr Opin Lipidol. 2011;22(2):129-36. doi:10.1097/MOL.0b013e32834477a9.

77. Resnick MD, Bearman PS, Blum RW, Bauman KE, Harris KM, Jones J, et al. Protecting adolescents from harm. Findings from the National Longitudinal Study on Adolescent Health. JAMA. 1997;278(10):823-32.

78. Harris KM. An integrative approach to health. Demography. 2010;47(1):1-22.

79. Miller WC, Ford CA, Morris M, Handcock MS, Schmitz JL, Hobbs MM, et al. Prevalence of chlamydial and gonococcal infections among young adults in the United States. JAMA. 2004:291(18):2229-36. doi:10.1001/jama.291.18.2229.

80. Harris KM, Halpern CT, Haberstick BC, Smolen A. The National Longitudinal Study of Adolescent Health (Add Health): Sibling pairs data. Twin Res Hum Genet. 2013;16(1):391-8. doi:10.1017/thg.2012.137.

81. Team AHB. Biomarkers in Wave III of the Add Health Study. Carolina Population Center; 2005:1-57. Available at: hhttp://www.cpc.unc.edu/projects/ addhealth/faqs/aboutdata/biomark.pdf/view. Accessed January 7, 2013

82. Monda KL, Chen GK, Taylor KC, Palmer C, Edwards TL, Lange LA, et al. A metaanalysis identifies new loci associated with body mass index in individuals of African ancestry. Nat Genet. 2013;45(6):690-6. doi:10.1038/ng.2608.

83. Goodman E, Hinden BR, Khandelwal S. Accuracy of teen and parental reports of obesity and body mass index. Pediatrics. 2000;106(1 Pt 1):52-8.

84. Kuczmarski RJ, Ogden CL, Guo SS, Grummer-Strawn LM, Flegal KM, Mei Z, et al. 2000 CDC growth charts for the United States: Methods and development. Vital Health Stat. 2002;11(246):1-190.

85. Cole TJ, Faith MS, Pietrobelli A, Heo M. What is the best measure of adiposity change in growing children: BMI, BMI\%, BMl z-score or BM centile? Eur J Clin Nutr. 2005;59(3):419-25.

86. Patrick DL, Cheadle A, Thompson DC, Diehr P, Koepsell T, Kinne S. The validity of self-reported smoking: A review and meta-analysis. Am J Public Health. 1994;84(7):1086-93.

87. Centers for Disease Control and Prevention. Youth risk behavior surveillance-United States, 2011. Morb Mortal Wkly Rep Surveill Summ. 2012;61(4):1-162.

88. Rees DL, Sabia JJ. Body weight and smoking initiation: Evidence from Add Health. J Health Econ. 2010;29(5):774-7. doi:10.1016/j.jhealeco.2010.07.002.

\section{Submit your next manuscript to BioMed Central and take full advantage of:}

- Convenient online submission

- Thorough peer review

- No space constraints or color figure charges

- Immediate publication on acceptance

- Inclusion in PubMed, CAS, Scopus and Google Scholar

- Research which is freely available for redistribution 